\title{
Determinants of Organizational Culture and Lean Thinking: Basis of a Post Pandemic Strategic Planning in Distribution and Retail Chain of Stores
}

\author{
Benita Aquino Meneses \\ Institute of Accounts, Business, and Finance, Far Eastern University, Manila City, Philippines \\ $\square$ Corresponding Author: Benita Aquino Meneses, E-mail: bmeneses@feu.edu.ph
}

\begin{abstract}
ARTICLE INFORMATION
Received: 01 September 2021

Accepted: 28 October 2021

Published: 07 November 2021

DOI: 10.32996/jbms.2021.3.2.19

\section{KEYWORDS}

Lean Thinking, Organizational Culture, Distribution and Retail Chain of Stores.

\section{ABSTRACT}

The study's goal was to give stakeholders information drawn from employees' lean thinking on organizational culture during a hostile moment, as well as to produce a strategic planning idea for the distribution and retail chain of outlets. To discover significant facts about the topic, a descriptive survey with a mixed qualitative and quantitative research approach was used. Employees of ten (10) corporations involved in distribution and retail chain stores in Metro Manila were polled for information, to learn about substantial and minor variances in employees' attitudes toward lean thinking in terms of organizational waste, as defined by the organizational culture in the workplace. Findings between lean thinking and business culture revealed significant disparities in employee status. It refers to personnel who, regardless of their job title, may contribute to the organization's waste. This research will be used as a foundation for strategic planning for supply networks in distribution and retail chains in any company industry during and after an adversarial phase.
\end{abstract}

\section{Introduction}

Lean Thinking refers to a tool used in the business to identify waste in an organization. Kanbanzone.com website, lean thinking is defined as a business philosophy that is based on the history of Japanese manufacturing processes that have been used in a variety of industries around the world. Lean focuses on continuously improving business processes to provide high customer value. Continuous Improvement and People Respect are two of these values in lean thinking. People can formulate and execute better business decisions and strategies that result in more productive systems for the organization when they frame their mindset on continuous improvement and respect. Adoption of improvement ideas and a lean culture opens up new possibilities for improving the quality and service of distribution networks and transportation and storage activities (Jaca and Santos, 2011).

According to the Lean Enterprise Institute website, the company has four different forms of waste. Process waste, information waste, physical environment waste, and people waste are the four types of waste. The methods of moving business from one functional field of the company to another are referred to as process waste. Waste affects the amount of time it takes to complete a job, the development process, the documentation process, and so on. For example, the approval process, bottlenecks, deadlines, flaws in the manufacturing process, incompatible systems, incompatible jobs, rigid hierarchy, excessive difficulty in task switching, useless details, waiting, and delays. Data waste which provides data or produces a particular duration of a company's results is another waste. Waste has a variety of negative effects, such as lost production, expensive delays and errors, and needless complexity. These may come from converting formats, data dead-end, data discrepancies, lack of usefulness, manually checking electronic data, missing data or re-entering data, unclear and incorrect data, and unknown data or unnecessary data. Waste products may become a by-product, joint product, or resource through an invention that raises a waste product's value above zero. When it comes to working environment waste, is about interruptions, moving/transportation, and an unsafe working environment. These three wastes would not be identified without people's intervention. They are employees of the organization involved in many aspects, including intellectual, norms, and values. Workforce waste potential can lead to employee turnover, increased absenteeism, and disengagement. These wastes are related to ineffective meetings, lack of project management, lack of training, lack of useful feedback, mishandled conflict, relearning, turnover, unclear roles, unclear sponsorship norms, and

Copyright: (c) 2021 the Author(s). This article is an open access article distributed under the terms and conditions of the Creative Commons Attribution (CC-BY) 4.0 license (https://creativecommons.org/licenses/by/4.0/). Published by Al-Kindi Centre for Research and Development, London, United Kingdom. 
boundaries, underutilization of talent, and most importantly is emotional waste that unnecessary comes frustration and stress of employees to the organization.

As stated in Kanbanize.com (2017) that, the lean retail sector focuses on customer value, analyzing both the whole life cycle of the product and the methods in which people operate to continuously find and eliminate sections of the firm that bring no value to the consumer. Additionally, all types of waste must be reduced, including errors that require rework, excessive manufacturing procedures, unnecessary transportation of materials or people, waiting time, excess inventory, and overproduction. This strategy is most commonly used by businesses to identify and eliminate waste in all aspects of the business process in accordance with corporate culture. The conduct, values, and beliefs of individuals inside the organization can be defined as organizational culture. This definition is useful in a variety of ways, including business strategy. A company's culture can be either its greatest advantage or its greatest liability. Culture described the competing values system in Ocai-online.com. The following are the four styles of organizational culture that emerged. First, culture creates a pleasant working atmosphere. People's dominant characteristics are cohesiveness, participation, coordination, and a sense of belonging. This culture's leadership typically acts as a mentor, facilitator, and parent figure. Most of them have conventional, trustworthy, and interpersonal links. Human resources, engagement, and morale are all areas where a strategic focus is placed. Second, culture creates a diverse and productive climate. Adaptive, imaginative, and integrative are the most popular characteristics of this society. Third, the culture promotes a results-oriented company that focuses on completing tasks and completing tasks. Competitiveness and goal achievement are the two most important characteristics of consumer culture. It focuses on market dominance and competitive advantage. Finally, the culture formalized and organized work environment. Because of the strategic focus on stability, predictability, and smooth operation, this is governed by order, rules and regulations, and uniformity (Racelis, 20015)

Another study's organizational culture is characterized by high organizational commitment and good working relationships among its employees, implying that employees are proud to be a part of their respective organizations and will do their best and support one another as a team to help the organization achieve its goals. It is also reflected in a well-planned organization with committed managers, defined organizational objectives, targets, and accessibilities of employees to opportunities (Kayode, Francis, and Ashipaoloye, 2014).

Similar to Kuepers's (2013) study said that organizational culture is the outcome of management and employee expectations, which include experiences, methods of thinking, beliefs, and future aspirations. This company-wide mindset may or may not have been apparent. It's a collection of widely held, often tacit assumptions, beliefs, and values that underpin people's ways of being relating, and working, as well as an organization's relationship with its working environment. Culture is a more powerful way of controlling and managing employee behaviors than organizational rules and regulations (Taherimashhadi \& Ribas, 2017)

The working environment which is part of strategic planning in supply chains is the main output of this study related to organizational culture in the business of selling and distributing products in various chain stores under concessionaire and consignment agreements and in the company's own outlet/shop is known as the distribution and retail chain of store. This industry defined in Britanica.com website describes that the chain store is any of two or more retail stores having the same ownership and selling the same lines of goods. Chain stores account for an important segment of retailing operations in the country or any place in the world. Together with the department store and the mail-order company, chain stores represent the first successful application of large-scale integrated methods to a form of retailing.

Over the years, companies have struggled to address challenges even before and midst of the pandemic that occurs in the supply chains operation work processes, including finance, marketing, human resources, accounting, warehouse, and logistics. The Institute for Supply Chain Management (ISM) describes supply chain management as: "the design and management of seamless, value-added processes across boundaries to meet real needs of the end of customer".

Store design, display placement, customer service, money and credit handling, shoplifting prevention, premises maintenance, staff management, inventory optimization, and dealing with the entire supply chain that leads to having products in the store are all aspects of business retail operations, according to the website of Smartstreet.com. These are the most common commercial transactions, and distribution and retail shop chains should focus on them. This supply chain has been defined as having a company culture that has unknowingly altered the wastes of the corporation.

Throughout the distribution and retail chain of stores phases of the company activity in this study, employees discovered organizational waste from lean thinking. It will lead to the development of a post-pandemic strategy plan for distribution and retail stores, in the form of preventive and corrective actions that may be implemented in the business to save time, money, effort, and energy. The focus of the researcher's scholarly investigation will be on indicators of lean thinking and organizational culture. 
Corporate strategy in the post-pandemic age must be coherent; in other words, it must be reasonable and achievable in light of the opportunities available and the competencies the firm has or will acquire. Instead of focusing on keeping things operating, leaders should focus on building people's ties to the organization's mission (Bouch, 2020).

The notion of the study, first what is the profile age, educational attainment, level of responsibilities, designated functional area, and employment status? Second, Is there a significant difference participants' lean thinking views on organizational culture thinking on organizational culture when it comes to [1] culture creates for a pleasant working atmosphere; [2] culture creates a diverse and productive climate; [3] culture promotes a results-oriented company that focuses on completing tasks and completing tasks; and [4] culture formalized and organized work environment according to its employment position? Lastly, there are no significant differences among the participants' assessment to the lean thinking of organization waste in terms of business [1] process, [2] transaction data, [3] working environment, and [4] workforces according to their profile.

This study also attempted to produce a basis of post-pandemic strategic planning for supply chains in the distribution and retail chain of stores, to make the organization a better place to work, work with common ideas, values, and management goals to become a sustainable business despite adversary.

\section{Methods}

The study was written using a novel descriptive survey and it was a combined qualitative and quantitative research to discover the concepts that delve into the mechanistic process. Participants of the study consisted of two hundred eighty-one (281) employees from different divisions of Group of Companies which involved ten (10) corporations situated in Quezon City. They were deployed in the Divisions of purchasing, human resources, warehouse and logistics, sales and marketing, finance, and accounting, where all the companies were engaged in distributions in the leading retail chain of stores and outlets in Metro Manila.

The instrument used was a questionnaire categorically divided into three (3) parts which were limited to; First, the profile of the respondents; Second, organizational culture in the workplace which were sub-categorically divided into [a] culture makes for a pleasant working atmosphere; [b] culture creates a diverse and productive climate; [c] culture promotes a results-oriented company that focuses on completing tasks and completing tasks; and [d] culture formalized and organized work environment Third, lean thinking of the employees' optic on organizational waste sub-categorically divided also into business process, transaction data, working environment, and workforces.

The participants answered the questionnaire by marking in given choices, rating them on a five-point scale of [5] Always which signifies as 'every day or more often', [4] Very Often or in as 'two to six times a week', [3] Sometimes which signify as 'once a week', [2] Rarely which signifies as 'less than once per week' and [1] Never which signifies as 'not at all', and an opportunity to add their remarks by filling-out "Others, please specify", and for easy comprehension by the participants, the instrument was written in two languages, English and Filipino. Due to the unexpected critical change of time, the researcher used Google forms, and then links were transmitted via any platform of social media using their respective personal email addresses to enable them to proceed in the survey. The data gathering was completed in the whole year period of the pandemic from June 2020 up to February 2021.

The proponent tabulates and processes the data using SPSS after retrieving the questionnaire. The data were described and analyzed using a Five-Point Likert Scale, Weighted Arithmetic Mean, and Percentage of Distribution during the throughput process. One-Way Analysis of Variance (ANOVA) was used to test the findings, and the F-test was utilized to see if there was a significant difference between the groups of participants. To evaluate the significance and non-significant level of the findings, differences were interpreted at a margin of error of 0.05 or $5 \%$.

\section{Results and Discussions}

Using SPSS, the persistent data from the study participants about corporate culture in relation to lean management was represented using cross-tabulation and descriptive statistics. The basic information to analyze and interpret the two variables as indicated by their responses in the survey was all data gathered from participants according to their profile - age, educational attainment, level of responsibilities, designated functional area, and employment status in the company - which resulted in the following:

Table 1.1

Distribution of Participants Profile - Age 


\begin{tabular}{lll}
\hline \multicolumn{1}{c}{ Age } & & Cumulative \\
& Frequency & Percent \\
\hline 20 years old \& below & 118 & 42 \\
30 to 40 years old & 109 & 39 \\
41 to 50 years old & 45 & 16 \\
51 to 60 years old & 9 & 3 \\
61 years old or above & 0 & 0 \\
\hline Total & 281 & 100 \\
\hline \hline
\end{tabular}

Table 1.1 shows the distribution of participant profiles by age. The poll was completed by 100 percent of those who took part, or 281 participants. The respondents who are 20 years old and under, 30 to 40 years old, and 41 to 50 years old have the highest frequency and cumulative percent of 118 (42\%) and 109 (39\%) respectively, while 45 (16\%) are 41 to 50 years old. Only 9 (3\%) of them are between the ages of 51 and 60 , with the lowest frequency and cumulative percent. Employees with younger years are more employable in the distribution and retail chain of stores sector, according to the research.

Table 1.2

Distribution of Participants Profile - Educational Attainment

\begin{tabular}{lll}
\hline & & Cumulative \\
Educational Attainment & Frequency & Percent \\
\hline Elementary School & 3 & 1 \\
Secondary School & 61 & 22 \\
Senior High School & 25 & 9 \\
Vocational/Undergrad & 108 & 38 \\
College Graduate & 50 & 18 \\
Post Graduate & 17 & 6 \\
Others & 17 & 6 \\
\hline Total & 281 & 100 \\
\hline \hline
\end{tabular}

Table 1.2 illustrates the distribution of educational attainment among the participants. The majority of the participants' educational attainment was vocational or undergraduate college, secondary high school, and college graduate, with frequencies and cumulative percents of 108 (38\%), 61 (22\%), and 50 (18\%) respectively. Senior high school employees accounted for 25\% (9\%) of the total, while postgraduate and participants defined themselves as "other" and undertook a 5-month training program with a cumulative percentage of 17 or $6 \%$. A small percentage of the participants are elementary school graduates, with a frequency and cumulative percent of 3 percent (1 percent).

\section{Table 1.3}

Distribution of Participants - Level of Responsibilities

\begin{tabular}{lll}
\hline & & Cumulative \\
Level of Responsibilities & Frequency & Percentage \\
\hline Rank and File & 257 & 91 \\
Supervisory Level & 14 & 5 \\
Managerial Level & 10 & 4 \\
\hline Total & 281 & 100 \\
\hline \hline
\end{tabular}

Table 1.3 depicts the distribution of participant profiles by the level of responsibility. Only 14 (5\%) are in supervisory positions, and 10 (4\%) are in managerial positions, with 257 (91\%) employed as rank and file. 
Table 1.4:

Distribution of Participants Profile - Designated Functional Area

\begin{tabular}{lll}
\hline & & Cumulative \\
Designated Functional Area & Frequency & Percentage \\
\hline HR and Administrative Personnel & 12 & 4 \\
Purchasing and Product Development Personnel & 7 & 2 \\
Sales and Marketing Personnel & 188 & 67 \\
Finance and Accounting Personnel & 14 & 5 \\
Warehouse and Logistics Personnel & 54 & 19 \\
Others & 6 & 2 \\
\hline Total & 281 & 100 \\
\hline \hline
\end{tabular}

Table 1.4 explains the distribution of participants' profiles as to their designated functional area. The largest numbers of participants designated to sales and marketing department; warehouse and logistics is with the frequency and cumulative percent of 188 (67\%) and 54 (19\%) respectively since this is the main focus of the group of companies in the distribution and retailing business, it is not surprising the results are majority employees are deployed to these two functional areas. The remaining participants are fairly evenly distributed among various functional areas, such as finance and accounting, human resources, and administrative, with 14 (5\%) and 12 (4\%) frequency and cumulative percent, respectively. While other functional areas are nearly as numerous as purchasing and product development, a small number of them are classified as "others," implying that they are unsure of which department they belong to, with a frequency and cumulative percent of 7 (2\%) and 5 (2\%) respectively.

Table 1.5

Distribution of Participants - Employment Status

\begin{tabular}{lll}
\hline & & Cumulative \\
Employment Status & Frequency & Percent \\
\hline Contractual & 130 & 46 \\
Project-Based & 8 & 3 \\
Probationary & 21 & 7 \\
Regular & 122 & 43 \\
\hline Total & 281 & 100 \\
\hline \hline
\end{tabular}

Table 1.5 shows the distribution of participants as to their employment status. The majority of them are contractual and regular with the frequency and cumulative percent of 130 (46\%) and 122 (43\%) while probationary and are project-based 21 (7\%) and 8 (3\%) correspondingly. The following tables and figures exhibit the intervening data of the factors of organizational culture and respondent evaluations of organizational culture in relation to lean thinking: 
Table 2.1

Culture Creates for a Pleasant Working Atmosphere

\begin{tabular}{|c|c|c|c|c|}
\hline \multicolumn{2}{|c|}{ Pleasant Working Atmosphere Indicators } & \multirow{2}{*}{$\frac{W X}{3.64}$} & \multirow{2}{*}{$\begin{array}{l}\text { DR } \\
\text { Very Often }\end{array}$} & \multirow{2}{*}{$\begin{array}{l}\text { Rank } \\
2\end{array}$} \\
\hline 1 & $\begin{array}{l}\text { When needed, the employee gets assistance from a } \\
\text { coworker. }\end{array}$ & & & \\
\hline 2 & $\begin{array}{l}\text { While on emergency leave, coworkers voluntarily do the } \\
\text { duties of another coworker. }\end{array}$ & 3.59 & Very Often & 3 \\
\hline 3 & $\begin{array}{l}\text { When a family occasion occurs, the specified job might be } \\
\text { delegated to a coworker. }\end{array}$ & 2.33 & Rarely & 6 \\
\hline 4 & $\begin{array}{l}\text { When the managers are not there, make small } \\
\text { conversations with coworkers. }\end{array}$ & 2.75 & Sometimes & 5 \\
\hline 5 & $\begin{array}{l}\text { To maintain a positive interpersonal relationship, assist a } \\
\text { coworker in meeting a deadline. } \\
\text { Create an escape goat to avoid being rushed to }\end{array}$ & 3.90 & Very Often & 1 \\
\hline 6 & $\begin{array}{l}\text { accomplish work at home. } \\
\text { They put off what they could do today in order to assist a }\end{array}$ & 1.89 & Rarely & 7 \\
\hline 7 & coworker in their work. & 1.88 & Rarely & 8 \\
\hline 8 & extent of affecting their task. & 2.80 & Sometimes & 4 \\
\hline 9 & Others, please specify & 2.00 & Rarely & 6 \\
\hline & Over-all Mean & 3.10 & Sometimes & \\
\hline
\end{tabular}

Legend:[5] 4.50 -5.00 Always; [4] 3.50 - 4.49 Very Often; [3] 2.50 - 3.49 Sometimes; [2] 1.50-2.49 Rarely; [1] Never $1.00-1.49$

Table 2.1 Illustrates the determinants of organizational culture creates for a pleasant working atmosphere which reveals the participants' view and described it as "very often" and the highest rank among the responses is "to maintain a positive interpersonal relationship, assist a coworker in meeting a deadline" with a mean of 3.90; while "when needed, the employee gets assistance from a worker"; and "while on emergency leave, coworkers voluntarily do the duties of another coworker" with mean of 3.64, and 3.59 respectively. According to them, "sometimes" they were "helpful, sympathetic, and caring to a co-worker to the extent of affecting their task" and "when the managers are not there, make small conversation with coworkers" with the garnered mean of 2.80 and 2.75. The rest of the participants rated other indicators as "rarely" and the lowest rank among the responses was "they put off what they could do today in order to assist a coworker in their work" with a mean of 1.88 and "create escape goat to avoid being rushed to accomplish work on home" with a mean of 1.89. Few of the participants answered as "others" with the remark "special and unidentified training attended". Culture makes for a pleasant working atmosphere shows an overall mean of 3.10, with a verbal interpretation of "sometimes".

Table 2.2

Culture Creates a Diverse and Productive Climate

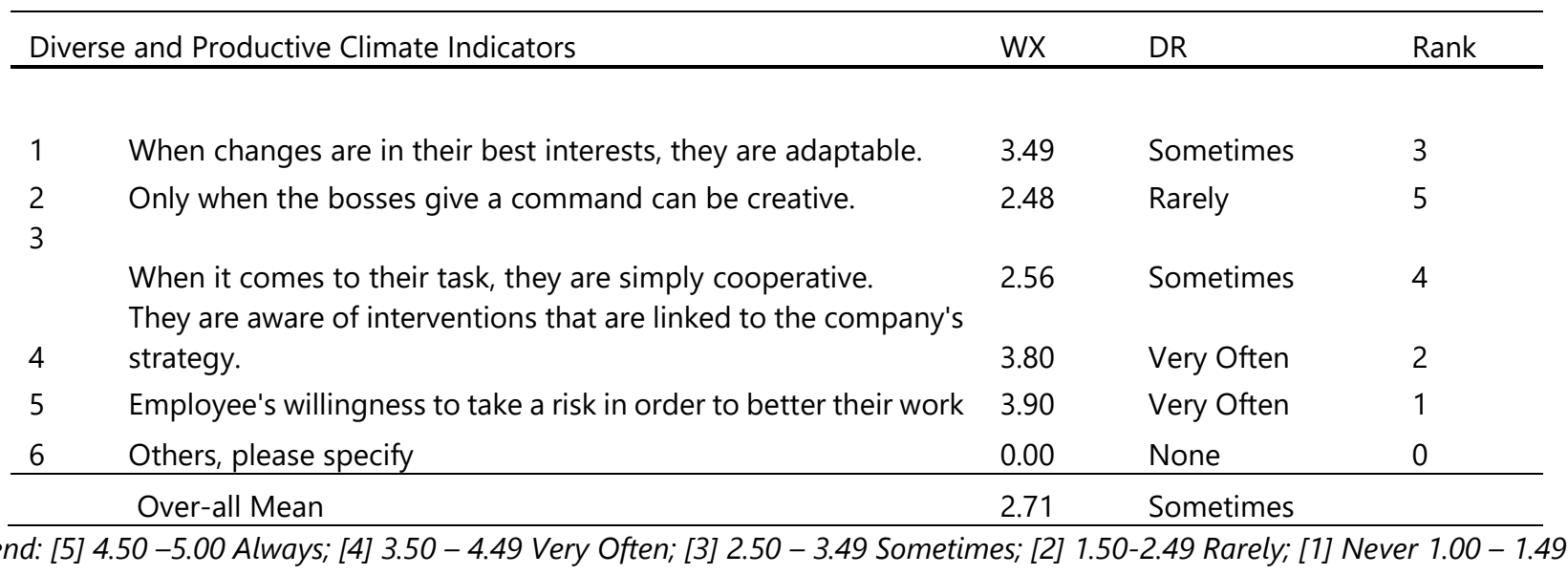


Table 2.2 shows the determinants of organizational culture as to creates a diverse and productive climate, the participants rated "very often" as the highest rank among the responses, "employee's willingness to take risk in order to better their work" and "they aware of interventions that are linked to the company's strategy" with a mean of 3.90 and 3.80, accordingly. However, "sometimes" they were "when changes are in their best interests, they are adaptable" and "when it comes to their task, they are simply cooperative" with the mean of 3.49 and 2.56, respectively. The lowest rank among responses was "rarely" which indicate that they are creative only when the bosses give a command can be creative" with a mean of 2.48. The variable culture creates a diverse and productive climate has an overall mean of 2.71 , with a verbal interpretation of 'sometimes".

Table 2.3

Culture Promotes a Results-Oriented Company that Focuses on Completing Tasks

\begin{tabular}{|c|c|c|c|c|}
\hline & Results-Oriented Indicators & \multicolumn{2}{|c|}{ Rank } & \\
\hline 1 & $\begin{array}{l}\text { Employee creativity, growth, and new resources for the } \\
\text { organization are all valued at work. }\end{array}$ & 3.89 & Very Often & 3 \\
\hline 2 & Competitive with the primary goal of achieving company success & 3.80 & Very Often & 5 \\
\hline 3 & $\begin{array}{l}\text { Have a spirit of collaboration with an evolving team system where } \\
\text { affiliation is the driving force. }\end{array}$ & 4.08 & Very Often & 1 \\
\hline 4 & $\begin{array}{l}\text { They are motivated to complete the tasks since their supervisor } \\
\text { is goal-oriented. }\end{array}$ & 4.05 & Very Often & 2 \\
\hline 5 & $\begin{array}{l}\text { Their ideas are centered on gaining a competitive advantage and } \\
\text { dominating the market. }\end{array}$ & 3.83 & Very Often & 4 \\
\hline 6 & Other, please specify & 0.00 & None & 0 \\
\hline
\end{tabular}

Legend:[5] 4.50 -5.00 Always; [4] 3.50 - 4.49 Very Often; [3] 2.50 - 3.49 Sometimes; [2] 1.50-2.49 Rarely; [1] Never 1.00 - 1.49

Table 2.3 demonstrates the determinants of organizational culture as to promote a results-oriented company that focuses on completing tasks. Participants ranked business culture as "very often" with the highest rank with the indicators "have a spirit of collaboration with an evolving team system where affiliation is the driving force", "they are motivated to complete the tasks since their supervisor is goal-oriented", "employee creativity, growth, and new resources for the organization are all valued at work" and their "ideas are centered on gaining a competitive advantage and dominating the market" with the mean range from 3.50 to 4.49 in all indicators of culture as to promotes a results-oriented company that focuses on completing the task with an over-all mean of 3.28 , with a verbal interpretation of "sometimes".

Table 2.4

Culture Formalized and Organized Work Environment

\begin{tabular}{cllll}
\hline Work Environment Indicators & WX & DR & Rank & \\
\hline 1 & Work is formal and well structured & 4.31 & Very Often & 2 \\
2 & Employees are dominated by order, rules, and regulation & 4.45 & Very Often & 1 \\
3 & There is uniformity in the business process & 4.23 & Very Often & 4 \\
4 & There is strategic regarding stability and predictability & 4.24 & Very Often & 3 \\
5 & There is a smooth operation & 4.24 & Very Often & 3 \\
6 & Others, please specify & 0.00 & None & 0 \\
Legend:[5] 4.50 -5.00 Always; [4] 3.50 - 4.49 Very Often; [3] 2.50 - 3.49 Sometimes; [2] 1.50-2.49 Rarely; [1] Never 1.00 - 1.49
\end{tabular}

Table 2.4 illustrates the determinants of organizational culture as to formalized and organized work environment. The participants scrutinized regularly "very often," with the highest rank being "employees are governed by order, laws, and regulation"; "work is formal and well structured"; "there is uniformity in the business process; there is strategic about stability and predictability"; and "there is smooth operation". Similar to results-oriented company culture with the mean of range from 3.50 to 4.49 in all indicators of formalized and organized culture with an overall mean of 3.58, its verbal interpretation is "very often". 
This section of the findings explains how respondents felt about organizational culture on lean thinking, which may lead to postpandemic strategic planning. According to the Lean Office website (2018), there are four types of waste found in the organization. These are business process waste, transaction data waste, work environment waste, and workforce waste.

Table 3.1

Participants' Lean Thinking on Organizational Culture as to Process Waste

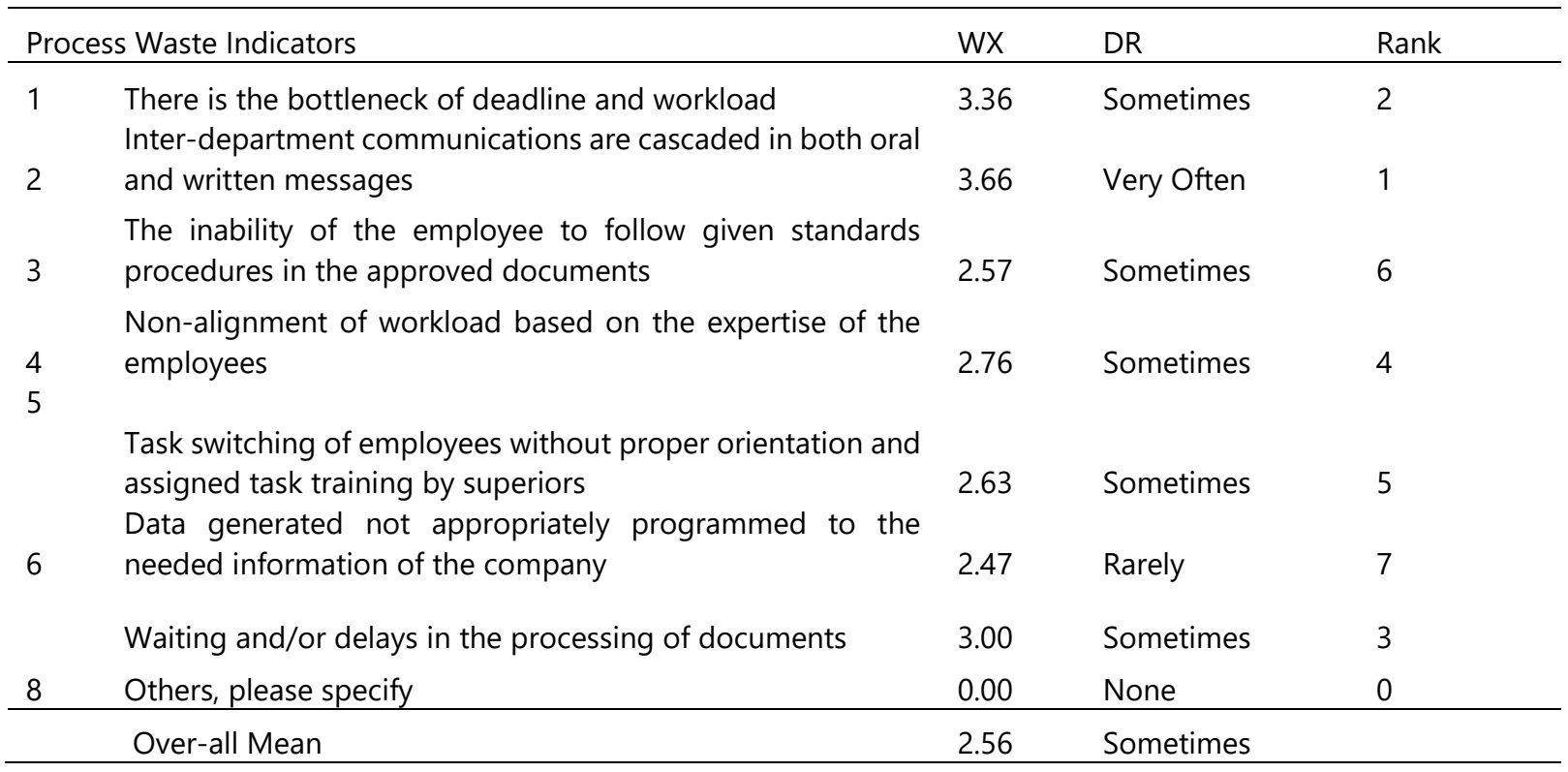

Legend:[5] 4.50 - 5.00 Always; [4] 3.50 - 4.49 Very Often; [3] 2.50 - 3.49 Sometimes; [2] 1.50-2.49 Rarely; [1] Never 1.00 - .49

Table 3.1 exemplifies the participants' lean thinking on organizational culture as to process waste. The highest-ranking of identified process waste garnered a mean of 3.66 which is answered "very often" indicating that inter-department communications are cascaded in both oral and written messages. The other process wastes are rated "sometimes" which according to the participants show that there is a bottleneck of deadline and workload; waiting and/or delays in the processing of documents; non-alignment of workload based on the expertise of the employees; task switching of employees without proper orientation and assigned task training by superiors; and the inability of the employee to follow given standards procedures in the approved documents. These wastes were scattered with the mean of $3.36,3.00,2.76,2.63$, and 2.57 correspondingly. Whereas data generated not appropriately programmed to the needed information of the company was rated "rarely" among of them with a low mean of 2.47. Process waste reveals an overall mean of 2.56 , with a verbal interpretation "sometimes".

Table 3.2

Participants' Lean Thinking on Organizational Culture as to Transaction Data Waste

\begin{tabular}{lllll}
\hline Information Waste & WX & DR & Rank \\
\hline 1 & Lack of uniformity of report format & 2.67 & Sometimes & 1 \\
& $\begin{array}{l}\text { Incompleteness and inaccuracy of needed data and } \\
2\end{array}$ & & & \\
3 & information & 2.67 & Sometimes & 1 \\
4 & Data and information discrepancies & 2.69 & Sometimes & 2 \\
5 & Dack of validity in electronic data due to the manual process & 2.64 & Sometimes & 3 \\
6 & Other, please specify & 2.60 & Sometimes & 4 \\
\hline & Over-all Mean & 0.00 & None & 0 \\
\hline
\end{tabular}

Legend:[5] 4.50 - 5.00 Always;[4] 3.50 - 4.49 Very Often; [3] 2.50 - 3.49 Sometimes; [2] 1.50-2.49 Rarely; [1] Never 1.00 - 1.49 
Another factor of lean thinking to the organization culture is transaction data waste. The participants rated these wastes "sometimes" when it comes to data and information discrepancies; lack of uniformity of report format; incompleteness and inaccuracy of needed data and information; data input is usually unclear and unknown and lack of validity in electronic data due to the manual process, these wastes having mean results ranging from 2.50 to 3.49 . Transaction data waste showed an overall mean of 2.21, verbal interpretation of "rarely".

Table $\mathbf{3 . 3}$

Participants' Lean Thinking on Organizational Culture as to Working Environment Waste

\begin{tabular}{lllll}
\hline \multicolumn{2}{l}{ Physical Environment Waste Indicators } & WX & DR & Rank \\
\hline 1 & $\begin{array}{l}\text { Disorderly arrangement of materials resources } \\
\text { Timing of shuttle service schedule inconvenient }\end{array}$ & 2.51 & Sometimes \\
2 & employees & 2.25 & Rarely & 4 \\
3 & Unhealthy conditions of office for employee & 2.34 & Rarely & 2 \\
4 & Improper use equipment & 2.28 & Rarely & 3 \\
5 & Others, please specify & 0.00 & None & 0 \\
\hline & Over-all Mean & 1.88 & Rarely \\
\hline d:[5] 4.50 -5.00 Always; [4] 3.50 - 4.49 Very Often; [3] 2.50 - 3.49 Sometimes; [2] 1.50-2.49 Rarely; [1] Never 1.00 - 1.49
\end{tabular}

Table 3.3 shows the participants' lean thinking on organizational culture in relation to lean management as to physical environment waste and people waste. Participants assessed the physical environment "sometimes" indicates the disorderly arrangement of materials resources which is the highest rank with a mean of 2.67. The rest of the physical wastes are rated "rarely" such as unhealthy conditions of office for employee, improper use equipment, and timing of shuttle service schedule inconvenient to employees which garnered mean ranging from 1.50 to 2.29 . Working environment waste with an overall mean of 1.88 as a "rarely".

Table 3.4

Participants' Lean Thinking on Organizational Culture as to Workforces Waste

\begin{tabular}{llllc}
\hline \multicolumn{2}{l}{ Workforces Waste Indicators } & WX & DR & Rank \\
\hline & $\begin{array}{l}\text { Unproductive meetings due to lack of feedback from } \\
\text { participants }\end{array}$ & 2.67 & Sometimes & 1 \\
2 & Lack of project management \& Training & 2.51 & Sometimes \\
3 & Mishandled conflict of employees by management & 2.60 & Sometimes & 3 \\
4 & Unclear specific roles of employees on given task & 2.64 & Sometimes & 2 \\
5 & Emotional waste due to unnecessary frustrations and stress & 2.60 & Sometimes & 3 \\
6 & Others, please specify & 0.00 & None & 0 \\
\hline & Over-all Mean & 2.17 & Rarely \\
\hline
\end{tabular}

Workforce waste, on the other hand, as participants replied to the survey, was "sometimes" unproductive meetings due to a lack of participant feedback; ambiguous basic positions of employees on a given task; emotional waste due to needless frustrations and stress; mishandled employee conflict by management; and a lack of project management and training. In relation to people wastes, this variable garnered a mean ranging from 2.50 to 3.49. Workforce waste showed an overall mean of 2.17 , with a verbal interpretation of "rarely". 
Table 4.1

One-Way ANOVA of Participants' Lean Thinking Views on Organizational Culture According to Group of Employment Status - Contractual, Project-Based, Probationary and Regular

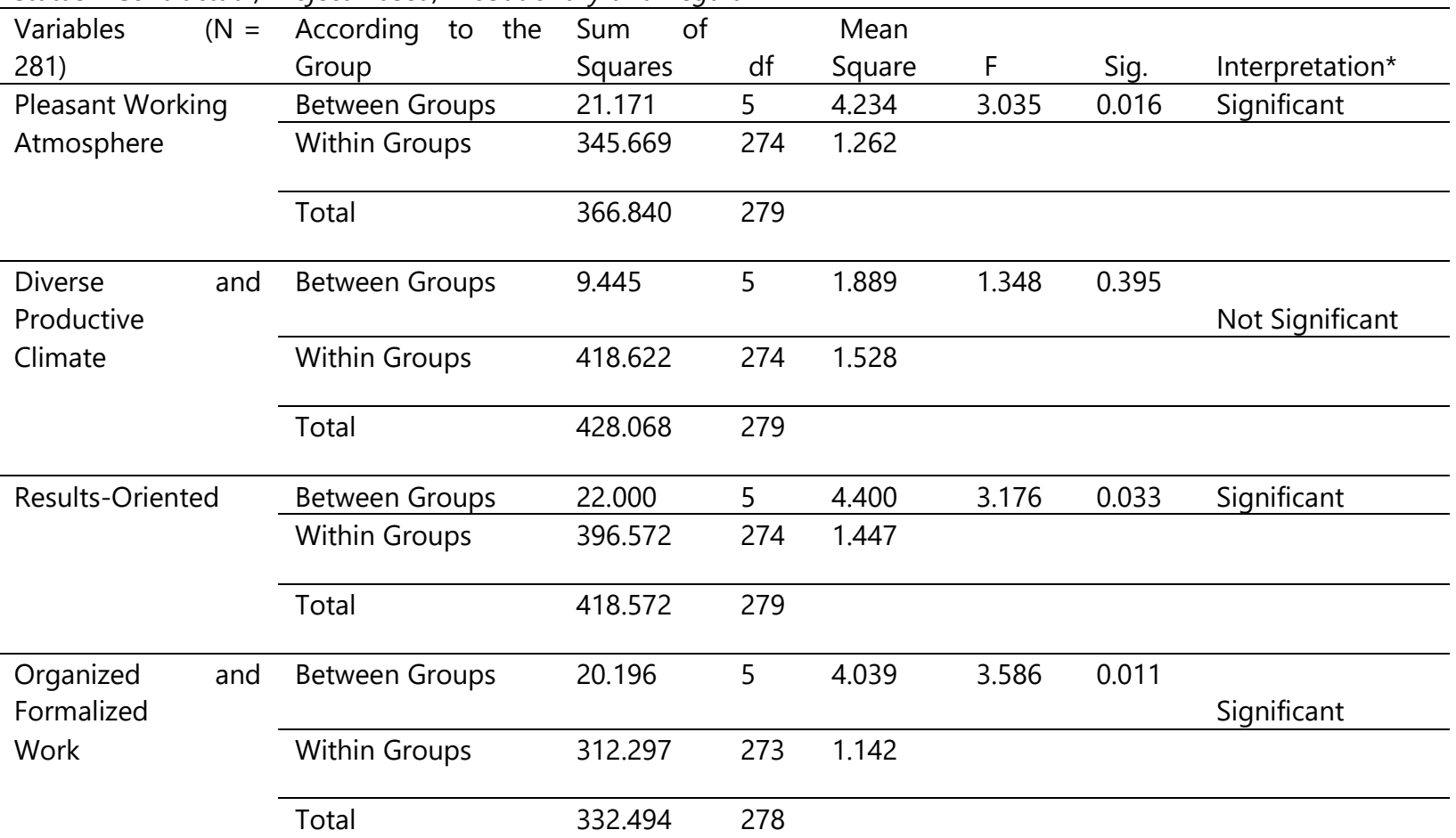

*Significant difference at the 0.05 level

Table 4.1 shows the results of a one-way ANOVA and F-test Model of organizational culture by job status, comparing participants who worked in one of four occupations. The significant difference between and within groups of employees $(F(5,274)=3.035$, $3.176,3.586), p<0.05)$. Tukey's HSD was used to determine the nature of their differences resulting to mean and standard deviation in terms of organizational pleasant working atmosphere, results-oriented, and organized and formalized, workers who had worked as contractual $(M=83.167$, $s d=27.150)$, project-based $(M=90.857$, $s d=26.824)$, probationary $(M=81.276, s d=26.427)$, and regular $(M=81.500, s d=18.188)$ were substantially different, although the diverse and productive climate was not significantly different between and within groups.

Table 4.2

One-Way ANOVA of Participants' Lean Thinking Views on Organizational Culture According to Group of Employment Status - Contractual, Project-Based, Probationary, and Regular

\begin{tabular}{|c|c|c|c|c|c|c|c|c|}
\hline $\begin{array}{l}\text { Variables } \\
281)\end{array}$ & $(\mathrm{N}=$ & $\begin{array}{l}\text { According to } \\
\text { the Group }\end{array}$ & $\begin{array}{l}\text { Suma } \\
\text { Squares }\end{array}$ & of & $\begin{array}{l}\text { Mean } \\
\text { Square }\end{array}$ & $\mathrm{F}$ & Sig. & Interpretation* \\
\hline \multirow{3}{*}{\multicolumn{2}{|c|}{ Process Waste }} & $\begin{array}{l}\text { Between } \\
\text { Groups }\end{array}$ & 17.092 & 5 & 3.418 & 2.234 & 0.142 & Not Significant \\
\hline & & Within Groups & 426.255 & 274 & 1.556 & & & \\
\hline & & Total & 443.347 & 279 & & & & \\
\hline \multirow[t]{3}{*}{$\begin{array}{l}\text { Transaction } \\
\text { Waste }\end{array}$} & Data & $\begin{array}{l}\text { Between } \\
\text { Groups }\end{array}$ & 9.548 & 5 & 1.910 & 1.242 & 0.340 & Not Significant \\
\hline & & Within Groups & 422.607 & 274 & 1.542 & & & \\
\hline & & Total & 432.156 & 279 & & & & \\
\hline $\begin{array}{l}\text { Working } \\
\text { Environment }\end{array}$ & & $\begin{array}{l}\text { Between } \\
\text { Groups }\end{array}$ & 7.236 & 5 & 1.447 & 0.908 & 0.546 & Not Significant \\
\hline
\end{tabular}




\begin{tabular}{|c|c|c|c|c|c|c|c|}
\hline \multirow[t]{2}{*}{ Waste } & Within Groups & 432.752 & 274 & \multicolumn{4}{|l|}{1.579} \\
\hline & Total & 439.988 & 279 & & & & \\
\hline \multirow[t]{5}{*}{ Workforce Waste } & Between & & 5 & & & & \\
\hline & Groups & 16.185 & & 3.237 & 2.167 & 0.142 & Not Significant \\
\hline & Within Groups & & 274 & 1101 & & & \\
\hline & & 408.669 & & 1.491 & & & \\
\hline & Total & 424.854 & 279 & & & & \\
\hline
\end{tabular}

*Significant difference at the 0.05 level

Table 4.2 depicts a One-Way ANOVA and F-test Model of lean thinking by job status, comparing participants who worked in one of four occupations. A significant difference between and within groups of employees $(F(5,274)=2.234,1.242,0.908,2.167), p<$ 0.05). Tukey's HSD was used to determine the nature of their differences. It was discovered that in terms of organizational waste of process, information, work environment, and workforce waste, employees working resulted to mean and standard deviation of contractual $(M=60.412, s d=26.931)$, project-based $(M=58.571$, $s d=38.099)$, probationary $(M=55.717, s d=24.150)$, and standard $(M=58.571, s d=18.798)$ were not substantially different both between and within groups.

\section{Conclusions and Implications}

This section summarizes the findings and illustrates the consequences for company supply chains involved in distribution and retail store networks are as follows:

Employees in the distribution and retailing industries were most employable when they were younger, and the majority were college or vocational graduates. When it came to job standards and placement qualifications, the company clearly followed industry trends. Furthermore, it was clear that there was a significant rate of staff turnover based on the number of regular workers.

The impact of lean thinking on corporate culture, according to the defined participants, has had a significant impact on lean operations during pandemics. Organizational culture and waste reduction through lean thinking were both disregarded in the distribution and retailing industries regardless of participants' age, educational attainment, levels of responsibilities, designated functional area, and employment status.

Employees' occupational positions were largely acknowledged in various perspectives on the organizational waste of lean thinking and organizational culture. As a result, employees are more likely to contribute waste related to processes, transaction data, working environment, and workforce waste. As a result, the company's culture has a significant impact on them before and midst of the pandemic.

Based on the findings, waste identified through lean thinking by employees during the distribution and retailing phases would be transformed into distinct business strategies for all functional areas of the organization, notably sales/marketing, warehousing, and logistics strategic planning for lean operations.

\section{Implications/Suggestions for Future Research}

The findings above lead to recommendations for future research and bases for post-pandemic strategic planning. Using lean thinking, they can be rectified and/or prevented.

First, management should recognize the existence of culture, as well as gain a better understanding of the business process, transaction data, working environment, and workforces, which they have sometimes overlooked by issuing directives that are frequently outside of standard procedures or never change to what they believe in for the organization before and midst of pandemic period.

Second, employees must be engaged in their work while also influencing the culture of the firm to eliminate waste in processes, transaction data, working environment, and workforces. As a result, key personnel in their designated functional areas in the business should remember that their role as delegated to them extends beyond simply supervising, monitoring, and evaluating their workers. It's also critical to aid the corporation in reducing waste through preventive and corrective actions.

Third, create a post-pandemic strategic plan that can be implemented in today's economic conditions as preventive and corrective actions through the use of the digital platform of virtually doing the business process, that focuses on distribution and retailing 
businesses in sales/marketing, warehouse, and logistics, as well as supply chain in the event of adversary period like a global pandemic.

Fourth, the environment should be a part of a business plan that involves not only growth but also corporate social duties to customers, especially the general public, by increasing exposure to the green principle of products now being supplied in the sector.

Lastly, the corporation should assess its organizational structure and work design to be an effective and efficient lean operation in the distribution and retail chain of stores after meeting the above-mentioned strategic planning.

\section{References}

[1] Bouch, M. (2020) "Covid - 19: Developing Strategy for the Post Pandemic Business World" https://www.hrdconnect.com/2020/05/12/covid-19developing-strategy-for-the-post-pandemic-business-world/

[2] Encyclopedia Britanica. https://www.britannica.com/topic/chain-store

[3] Institute of Supply Chain Management (ISM). "Supply Chain Management" https://www.ioscm.com/

[4] Jaca, C., Santos J, E., and Viles, E (2011). "Lean Thinking with Improvement Teams in Retail Distribution: A Case Study". https://www.researchgate.net/publication/241740500 Lean thinking with improvement teams in retail distribution A case study

[5] Kayode, F and Ashipaoloye (2014). An article on "A Comparative Analysis of the Organizational Culture and Employee's Motivatio/n of Selected Cities in CALABARZON: Basis for Employee's Motivation, Leadership, and Innovative Management". Published by Asia Pacific Journal of Multidisciplinary Research P-ISSN 2350-7756 | E-ISSN 2350-8442 | www.apjmr.com | Volume 2, No. 5, October 2014.

[6] Kanbanize.com (2015). "What is lean management? Definition and Benefits", https://kanbanize.com/lean-management/what-is-leanmanagement

[7] Kuepers, W (2013). An article on "Between the Visible and the Invisible in Organizations", published by ResearchGate.com, January 2013.

[8] Lean Enterprise Institute. https://www.lean.org/LeanPost/Posting.cfm?LeanPostld=352

[9] Racelis, A. R. (2005). An article on "An Exploratory of Organizational Culture in the Philippines Firms", published in Philippines Management Review2005, Vol. 12, 72-86.

[10] Ocai.-online.com. "Competing Values Framework 4 Organizational Culture Types emerged: Clan Culture, Adhocracy Culture, Market Culture, and Hierarchy Culture".https://www.ocai-online.com/about-the-Organizational-Culture-Assessment-Instrument-OCAl/OrganizationalCulture-Types

[11] Smartsheet.com, "Comprehensive Guide to Retail Store Operations: Today and in the Future". https://www.smartsheet.com/retail-storeoperations

[12] Taherimashhadi, M \& Ribas, I. (2017). "A Model to Align Organizational Culture to Lean Culture", Journal of Industrial Engineering and Management JIEM, 2018 - 11(2): 207-221 - Online ISSN: 2013-0953 - Print ISSN: 2013-8423. 